\title{
Numerical Analysis of Deformation Characteristic of Deep and Soft Ground under Vacuum Preloading
}

\author{
Xu Binbin * \\ Key Lab. of Geotechnical Engineering of Tianjin; Key \\ Lab. of Geotechnical Engineering \\ Tianjin Port Engineering Institute Ltd. of CCCC; \\ Tianjin, China \\ xubinbin@tpei.com.cn
}

\begin{abstract}
Based on the soil-water coupled finite element analysis, the vacuum consolidation of soft reclaimed ground is investigated systematically. The engineering background, ground profiles and improvement scheme are firstly introduced in detail, which is also a preparation for the following numerical calculations. Through a series of calculations, the deformation characteristics of the deep-soft ground can be captured numerically, which is also very close to the practical engineering. The results show that 1) with the duration of the vacuum preloading, the ground of the improved area deforms like a boiler, which is in accordance to the practical engineering; 2) The decreasing rate gradually decreases as the ongoing preloading and the pore pressure keeps almost stable at the end of the vacuum preloading; 3) The influence area of the vacuum preloading can be approximately estimated through the contours.
\end{abstract}

Keywords- deep-soft ground; vacuum preloading; fe method; long-term settlement; deformation charactoristic

\section{ENGINEERING BACKGROUND}

In China, there is about over $1.0 \times 10^{8} \mathrm{~m} 2$ reclaimed ground and in most of these areas the vacuum consolidation with plastic vertical drain is employed due to its easier equipment and shorter consolidation time. In order to understand the physical and mechanical properties of the soft soil, plenty of scholars have devoted their efforts to analyze the ground improvement by vacuum consolidation. Dong et al. [1] analyzed the variation of the permeability co-efficient with the void ratio and presented a single-well calculation with Abaqus. Ying \& Chen [2] proposed a two-stage vacuum consolidation method for the ultra-soft ground treatment, namely first very short plastic vertical drain is used for the surface layer of the ultra-soft ground and after there is certain bearing capacity in the surface layer then put longer plastic vertical drain for the consolidation of deeper layers. Qiu et al. [3] believed that the permeability coefficient of ultra-soft soil is changeable accompanying the progress of ground consolidation and put emphasis upon the influence of variable effective stresses on the permeability. However, no systematic numerical analyses, namely from the mesh partition, parameter determination to numerical computation until output of calculation results, are carried out due to the limitation of constitutive models or numerical methods for the soft dredged ground [4-10].

\author{
Si Wei \\ Technical Department \\ Tianjin Port Engineering Institute Ltd. of CCCC \\ Tianjin, China \\ * Corresponding Author
}

In the field, the depth of the soft soil is over $20 \mathrm{~m}$ and the vacuum preloading is adopted to improve the ground. In order to guide the practical construction, it is necessary to conduct series finite element calculations before the construction.

\section{GROUND PROFILES AND IMPROVEMENT SCHEME)}

\section{A. Ground profiles}

According to the ground exploring and drilling holes, the depth of the soft soil is very thick. The soil can be classified into six kinds along the depth, including filling, sludge, silty clay, alluvial soil, diluvial soil, completelyweathered moorstone, and the details are described as follows: 1) the depth of filling is between $0-5 \mathrm{~m}$, and the number of SPT is be-tween 3-8;2) the sludge is saturated and in a fluid plastic state; the tip resistance of static sounding is around $0.24-0.39 \mathrm{MPa}$ and the number of SPT is usually lower than 2 , which is a very soft soil; 3 ) the silty clay is in a plastic state and the depth is around 17$20 \mathrm{~m}$; the tip resistance of static sounding is around 0.91.3MPa and the number of SPT is usually between $8-14 ; 4$ ) the alluvial soil is saturated mixture between sand and clay; the tip resistance of static sounding is around $1.85 \mathrm{MPa}$ and the number of SPT is usually between $6-16 ; 5$ ) the diluvial soil is mainly medium coarse sand under saturated and medium-dense state; the tip resistance of static sounding is around $2.51 \mathrm{MPa}$ and the number of SPT is usually between 13-26.

According to the experimental results, the soil parameters can be determined and listed in TAB .1.

TABLE I SOIL PARAMETERS SUGGESTED B Y INDOOR EXPERIMENT

\begin{tabular}{c|c|c|c|c}
\hline Soil name & $\begin{array}{c}\text { Modulus of } \\
\text { compression } \\
(\mathrm{MPa})\end{array}$ & $\begin{array}{c}\text { Cohesion } \\
(\mathrm{kPa})\end{array}$ & $\begin{array}{c}\text { Internal } \\
\text { frictional } \\
\text { angle }\end{array}$ & $\begin{array}{c}\text { Characteristic } \\
\text { value of } \\
\text { subgrade } \\
\text { bearing }(\mathrm{kPa})\end{array}$ \\
\hline filling & 1.9 & - & - & $25 \sim 35$ \\
\hline sludge & 1.62 & 5.7 & 1.3 & $25 \sim 35$ \\
\hline silty clay & 5.46 & 27 & 6 & $130 \sim 140$ \\
\hline $\begin{array}{c}\text { alluvial } \\
\text { soil }\end{array}$ & 4.85 & 2 & 20 & $80 \sim 100$ \\
\hline diluvial & 18 & 1 & 25 & $180 \sim 200$ \\
\hline \hline soil & 9.1 & - & - & $230 \sim 250$ \\
\hline moorstone & & & & \\
\hline
\end{tabular}


should be transferred equivalently to satisfy the plane strain condition.

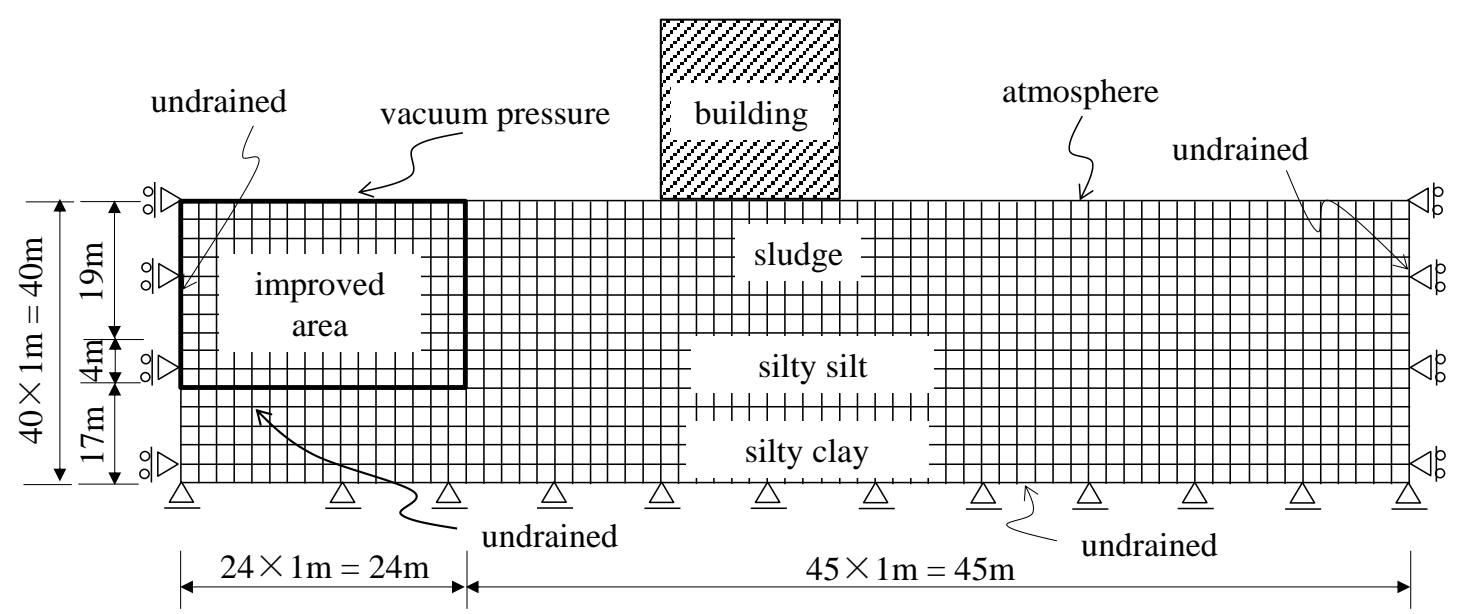

Figure 1. Numerical model and boundary conditions

\section{B. Improvement scheme}

As to the design materials, the total area of the soft soils is around $9960 \mathrm{~m} 2$. The type of plastic vertical drains is $\mathrm{C}$ type of SPB and the distance between two drains is $1.0 \mathrm{~m}$ with a depth of $25 \mathrm{~m}$. A distribution of regular triangle is adopted. In order to prevent the possible horizontal displacement and to obstruct the escape of vacuum pressure, the double-row cement mixing piles are installed as the sealing wall and the supporting structure. The diameter of the cement mixing pile is $700 \mathrm{~mm}$ and the distance between two plies is $500 \mathrm{~mm}$, the depth of which into the sludge layer should be larger than $3.0 \mathrm{~m}$. Initially, the vacuum pressure should be kept for about 5 7 days until the pressure under the sealing membrane reaches $80 \mathrm{kPa}$ and then the vacuum pressure is kept constantly for $120 \mathrm{~d}$ to accelerate the drainage of soft ground. When the ground bearing capacity after improvement is larger than $80 \mathrm{kPa}$ and the average consolidation degree of the improved depth is larger than $90 \%$, the vacuum pressure can be stopped.

\section{NUMERICAL MODEL}

According to the plane figure of the design document and the drill column, the relative position be-tween the improved area and the building is shown in Fig .1 and the classification of the ground is di-vided into sludge and silty clay. Considering the symmetry of the model, half of the model is used and the simplified plane strain condition is adopted. As can be seen, the width and the depth of the improved area are $24 \mathrm{~m}$ and $23 \mathrm{~m}$ respectively. The depth of the sludge and the silty clay are $23 \mathrm{~m}$ and $17 \mathrm{~m}$ respectively. At the top of the improved area, the vacuum pressure of $80 \mathrm{kPa}$ is applied to form the pressure boundary. For other top surface, the atmosphere boundary is adopted. The impermeable boundary is designated to the two side surfaces and the bottom. The height and the width of the building are $18 \mathrm{~m}$ and $10 \mathrm{~m}$ respectively. The distance between the improved area and the building is $15 \mathrm{~m}$. Considering that the building is a three dimensional structure, the weight and the stiffness of the building

\section{CALCULATION RESULTS}

\section{A. Settlement}

Fig .2 shows the settlement at the ground surface and the middle of the plastic vertical drain until 120d after the application of the vacuum pressure. As can be seen, the maximum settlement is about $1.8 \mathrm{~m}$. Before $90 \mathrm{~d}$, the settlement rate is relatively large under the action of the vacuum pressure, after which the rate gradually decreases. Through comparing the settlement at the middle of the drain, the settlement of the upper half part is as large as $0.5 \mathrm{~m}$, which consists of $28 \%$ total settlement. In order to forecast the long-term settlement, the improvement time is added until 300d and the corresponding settlement is demonstrated in Fig .3. As can be seen, the settlement rate is less than $1 \mathrm{~mm} / \mathrm{d}$ and the settlement becomes constant gradually. It can be regarded as the finish of the consolidation and the consolidation degree reaches $100 \%$, according to which the degree of consolidation at $120 \mathrm{~d}$ is about $95 \%$.

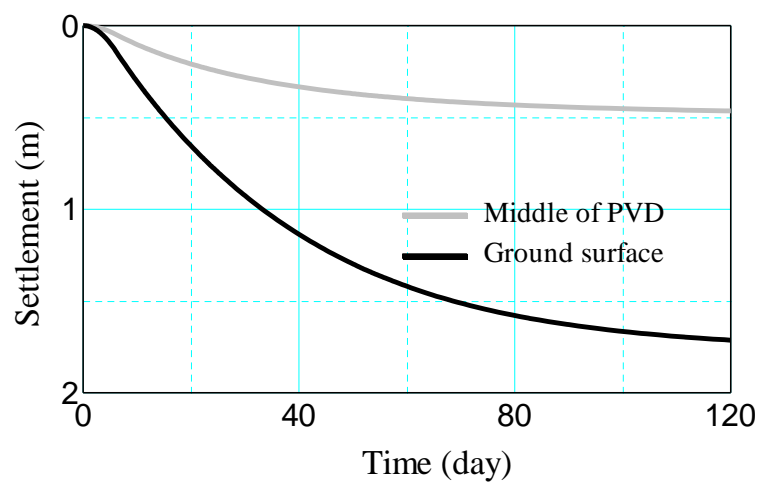

Figure 2. Settlement at different layers 


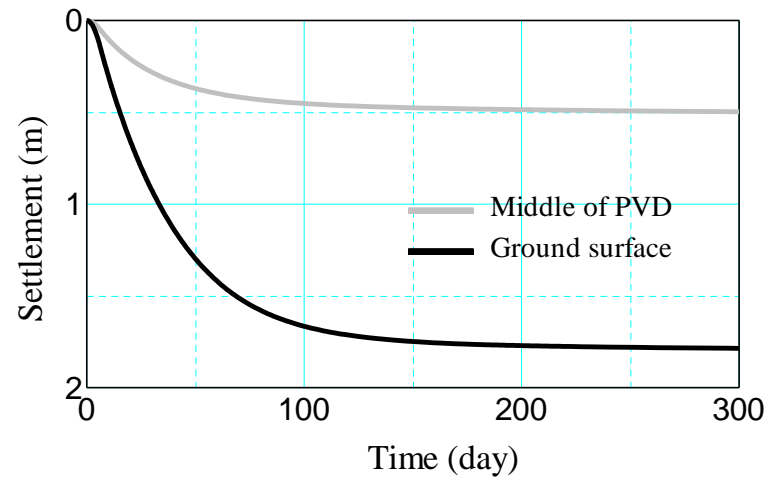

Figure 3. Long-term settlements at different layers

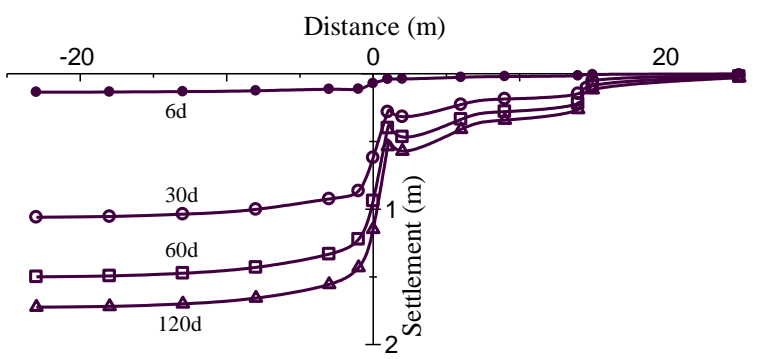

Figure 4. Settlement at ground surface at different stages

Meanwhile, in order to observe the ground deformation both inside and outside the improved area, the ground settlement at different consolidation time is shown in Fig .4. The horizontal axis represents the distance from the borderline of the improved area, where the positive and the negative mean the outside and the inside of the improved area respectively. As can be seen, with the duration of the vacuum action, the ground surface deforms like a boiler with large settlement on at the middle of the improved area. The farer the distance from the middle of the improved area, the smaller the settlement is. Due to the high water content of the sludge in the field, even in the very beginning, namely $6 \mathrm{~d}$ after the application of the vacuum pressure, there is already significant settlement at the middle of the improved area, with a magnitude about $13.5 \mathrm{~cm}$. Until $30 \mathrm{~d}$, the maximum settlement at the ground surface has reached $1 \mathrm{~m}$ and it can be ascribed to the accelerated drainage with the aid of the plastic vertical drains.

\section{B. Pore water pressure}

Fig .5 demonstrates the variation of pore water pressure at different depth $0.5 \mathrm{~m}, 4.5 \mathrm{~m}, 6.5 \mathrm{~m}, 8.5 \mathrm{~m}$. As can be seen, there is a similar tendency for all the pore pressure. In other words, at the initial period the pore pressure decreases rapidly and when it comes to the middle of the improved stage the decrease rate gets small gradually and at the end the dissipation of the pore water pressure keeps almost constant. From the ground surface to the deeper ground, the dissipation of the pore pressure is $63,68,70.6$, $72 \mathrm{kPa}$ respectively.

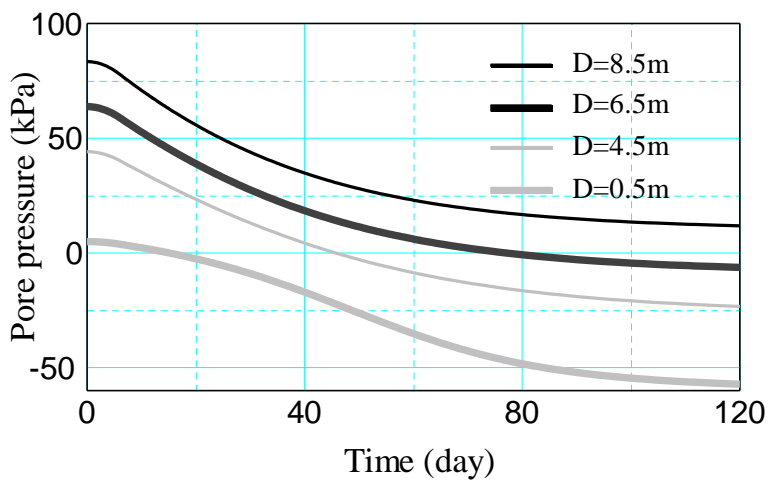

Figure 5. Variation of pore pressure and time at different depths

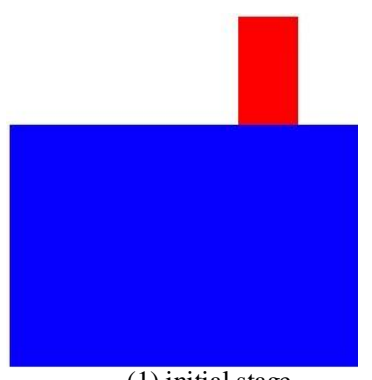

(1) initial stage

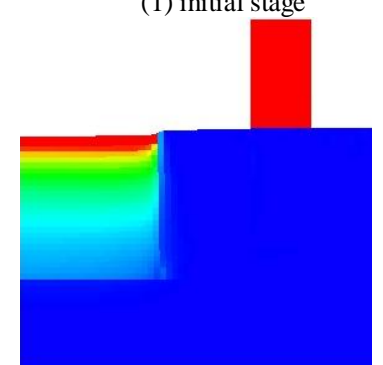

(3) 60d vacuum preloading $-0.4$

Figure 6. Distribution of volumetric strain in the ground

\section{Contours}

Fig .6 shows the distribution of the volumetric strain in the ground at different stages. In the legend, the blue means that the volumetric strain is zero and the red means $40 \%$ volumetric strain. It should be explained that due to the defect of the display in the posttreatment the volumetric strain of the building is also $40 \%$, but actually it should be zero. As can be seen, when the vacuum pressure is applied initially, the sludge at the surface layer is compressed quickly and the volumetric strain reaches the maximum. As the vacuum pressure transfers towards the deeper ground, the volumetric strain gradually diffuses from the ground surface to the deep ground. Meanwhile, for the range $1 \mathrm{~m}$ outside the improved area the soil outside the cement mixing pile is also compressed significantly due to the constraint of the cement mixing pile. The building gradually inclines towards the inside of the improved area due to the horizontal displacement of the outside ground.

The distribution of shear strain in the ground at different stages is shown in Fig .7. In the legend, the blue means zero and the red means $10 \%$ shear strain. It can be seen that the shear strain begins to occur at the surface 
layer at the initial stage. In addition, there is also significant shear strain between the improved area and the building. Because of the constraint of the building, the ground is deformed obviously at the two corners of the building with a larger shear strain at the corner near the improved area, as shown in Fig .7.

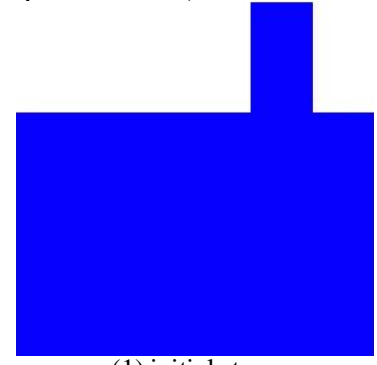

(1) initial stage

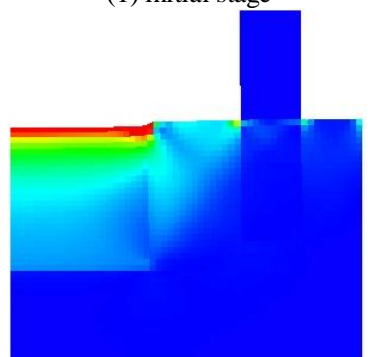

(3) 60d vacuum preloading 0.00

Figure 7. Distribution of shear strain in the ground

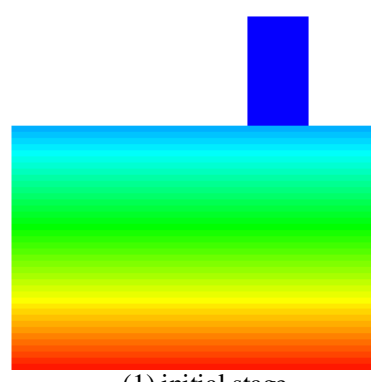

(1) initial stage

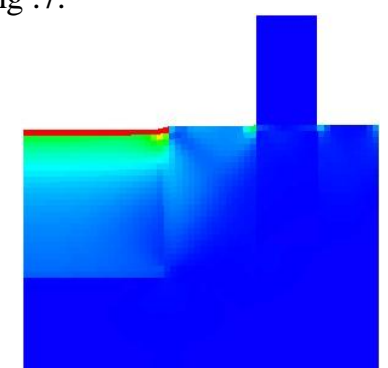

(2) 30d vacuum preloading

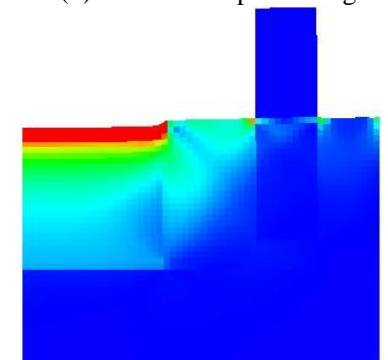

(4) $120 \mathrm{~d}$ vacuum preloading 0.10

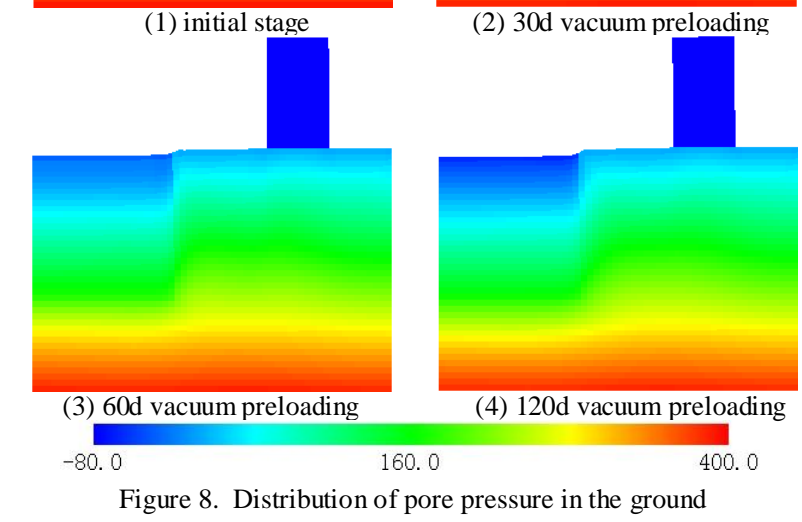

Fig .8 illustrates the distribution of the pore water pressure in the ground at different stages. In the legend, the blue represents $-80 \mathrm{kPa}$ and the red means $400 \mathrm{kPa}$. It should also be explained that due to the defect of the posttreatment program, there is $-80 \mathrm{kPa}$ pore pressure in the building, but actually there is no pore pressure. As can be seen, the distribution of pore pressure obeys the hydraulic pressure. As the action of the vacuum pressure, negative pore pressure begins to occur at the ground surface and it gradually expands towards deep ground due to the drainage of the plastic vertical drain.

\section{CONCLUSIONS}

A finite element analysis is carried out to investigate the deformation characteristics of soft ground using vacuum preloading. The ground settlement, pore pressure and contours are displayed respectively and the conclusions are as follows:

(1) When the vacuum preloading is applied until 120d, the maximum settlement at the ground surface is about $1.8 \mathrm{~m}$. Comparing with the settlement at $300 \mathrm{~d}$, it can be known that the consolidation degree at $120 \mathrm{~d}$ is over $95 \%$. With the duration of the vacuum preloading, the ground of the improved area de-forms like a boiler, which is in accordance to the practical engineering.

(2) For the pore pressure, it decreases rapidly due to the vacuum preloading at the initial stage. The de-creasing rate gradually decreases as the ongoing pre-loading and the pore pressure keeps almost stable at the end of the vacuum preloading. From the ground surface downwards, the dissipations of the pore pressure are 63, 68, 70.6 and $72 \mathrm{kPa}$ respectively.

\section{REFERENCES}

[1] Dong, Z. L., et al.. "Effects of permeability coefficients on consolidation of soft clay under vacuum preloading," Rock and Soil Mechanics, vol. 31, No. 5, 2010, pp. 1452-1456. (in Chinese)

[2] Ying, S. and Chen, P. S, "Effects of bended plastic drainage plates on consolidation caused by vacuum preloading," Chinese Journal of Rock Mechanics and Engineering, vol. 30, 2011, pp. 3633-3640. (in Chinese)

[3] Qiu, C. L., et al., "Effects of varying void on consolidation of dredger fill under vacuum preloading," Rock and Soil Mechanics, vol. 34, No. 3, 2013, pp. 631-638. (in Chinese)

[4] Leong E. C. et al.'Improvement by sureharge and vacuum preloading," Geotechnique, Vol. 5, 2000, pp.601-605

[5] Chu J, et al., Soil improvement by vacuum preloading method for oil storage station," Geotechnique. vol. 6, 2000, pp. 34-36

[6] Chai J. C., Shen S. L., Miura N. and Bergado, D. T. "Simple method of modelinU PVD-Improved subsoill," J. Geotech. and Geoenviron. Engrg. ASCE. vol. 11, 2001, pp.965-972

[7] Bergado D. T. et al. "Prefabricated vertical drains in soft Bangkok clay: a case study of the new Bangkok international airport project,” Can. Geotech. J., vol. 2, 2002, pp.304-315

[8] Kim Y.T. and Lee S.R. "An equivalent model and back-analysis technique for modeling in situ consolidation behavior of drainageinstalled soft deposits," Computer and geotechnics, vol. 2, 1997, pp. 125-142

[9] Rujikiatkamjorn C. Indraratna B. Chu J. "Numerical modeling of soft soil stabilized by vertical drains combining surcharge and vacuum preloading for a storage yard," Canadian Geoteehnical Journal, vol. 44, 2007, pp.326-342

[10] Masse, F. et al. Vacuum consolidation: a review of 12 years of suceessful development. Prepared for distribution to attendees at Geo-Odyssey-ASCE/VirginiaTech-Blaeksburg, VAUSA,June 9-13, 2001 